Cita: Gómez Solís, Felipe (2006): "Los provincialismos de Córdoba en los diccionarios académicos", en Mar Campos Souto e Ignacio Pérez Pascual, eds., El diccionario de la Real Academia Española: ayer y hoy, A Coruña, Universidade da Coruña, Anexos de Revista de Lexicografía, 1, pp. 117-128. https://doi.org/10.17979/spudc.9788497497466.117

\title{
Los provincialismos de Córdoba en los diccionarios académicos
}

FELIPE GÓMEZ SOLÍS

Universidad de Córdoba

(cc) BY-NC-SA

0. La introducción de provincialismos y regionalismos en los diccionarios generales de lengua, académicos y regionales constituye uno de los problemas a los que debe enfrentarse la lexicografía moderna y dialectal. Tal problema no es nuevo, pues en 1944 Julio Casares se hacía eco de la inundación de regionalismos en El idioma como instrumento y el diccionario como símbolo, al afirmar:

Ahora bien, ese común patrimonio lingüístico quedaría poco menos que sumergido si no se pusiera algún dique a la inundación de regionalismos procedentes de acá o de allá.

Y a lo que advertía del peligro de

convertir el Diccionario de la Lengua en un laberíntico mamotreto, donde habría veinte nombres para cada cosa (planta, animal, idea u objeto) y cada expresión correspondería a veinte cosas diferentes. El consultante, a quien solamente sería asequible una pequeña parte de ese acervo, no podría sustraerse a la impresión deprimente de hallarse ante una lengua desconocida, aunque semejante en algunos puntos a la española.

No obstante, se preguntaba y se contestaba de forma categórica:

¿Se ha de sacar de aquí la consecuencia de que conviene renunciar al acopio minucioso y paciente de los datos lingüísticos locales? De ningún modo.

De aquella fecha, pasamos a esta de 2003 con un trabajo de Salvador «Los dialectalismos en los diccionarios», en donde habla de la necesidad metodológica de establecer en lexicografía «una distinción entre dialectalismos muy extendidos y de 
uso habitual y frecuente en determinadas áreas geográficas, y meros localismos de escasa difusión y uso muy limitado» (2003: 215). Esta ha sido la interpretación de los diccionarios académicos a partir de la conclusión de que no han sido tantas las marcas regionales incorporadas en ellos, aunque sí frecuentes y de ámbito más o menos general dentro de la región o provincia, desde sus inicios en el Diccionario de Autoridades, certificadas en el punto noveno del prólogo quinto y puestas de relieve por Salvador Rosa (1985), Salvador (2003: 210, 211), Lázaro Carreter (1972: 42), Fernández-Sevilla (1974), Alvar Ezquerra (1984 y 1993), Martínez (1996: 31-41) o Ahumada (1998: XI-XXXv), entre otros. Y así hasta hoy en las sucesivas ediciones de los diccionarios académicos en sus diferentes variedades.

1. Aunque se han apuntado diferentes sentidos a los provincialismos y conceptos relacionados como dialectalismos, regionalismos, localismos (Alvar 1979; Alvar Ezquerra 1993: 317-318), se ha acudido al dado por la Academia, aunque presente algunas objeciones. La primera aparición de la voz tiene lugar en el diccionario de 1852 (DRAE-1852) $)^{1}$ con una extensión muy amplia: «Los modismos propios de cada provincia» (acep. 2) y que se repite en la siguiente de 1869: «Cualquiera de los modismos propios de cada provincia» (acep. 2). La actual data del diccionario de 1884 (DRAE-1884): «Voz ó giro que únicamente tiene uso en una provincia ó comarca de un país o nación», y que ha llegado sin apenas cambios pasando por los diccionarios usual y manual:

Voz o giro que únicamente tiene uso en una provincia o comarca de un país o nación (acep. 2 del DRAE-2001).

Aquí se ha sustituido «modismos» por «voz o giro», que es mucho más preciso y, además, se añade la mención «únicamente», que entronca con el valor de la existencia de marcas:

que la indicación «cero» de localización geográfica (en oposición a «Álava», «Andalucía», «Río de la Plata», etc.) significa que la voz pertenece al español general de todas las tierras hispanohablantes (Seco 2003: 28).

Y que viene a recogerse en las «Advertencias para el uso de este diccionario» de la vigente edición (2.2. xxxIv):

\footnotetext{
1 Para el examen de los diccionarios académicos, nos servimos del NTLLE.
} 
Todas aquellas entradas de uso general en España cuyo empleo en otros países ha sido expresamente negado por las Academias correspondientes, llevan la marca Esp.

No obstante, la definición académica de provincialismo de «Voz o giro que únicamente tiene uso en una provincia o comarca de un país o nación» es imprecisa al existir provincialismos que son exclusivos de una determinada provincia y que no se dan en otras («voz o giro que únicamente tiene uso en una provincia») como, por ejemplo, los cordobeses agraz, andrehuela, costumbre, lagareta, seda, revezo, temporera o trompillo (se hallan únicamente en Córdoba) y no serían tales aquellas palabras cuya marca aparece unida a otras provincias, como amolanchín, barril, descuidar, faisán ${ }^{1}$, ganga ${ }^{2}$, gallinita, geranio (de sardina), hormazo², peinilla, pintar, rezago, sufra o verdear: se encuentran también en otras provincias andaluzas (Almería, Cádiz, Granada, Jaén, Málaga, Sevilla) y en otras zonas españolas (Álava, Aragón, Burgos, Navarra, Palencia, Rioja) e hispanoamericanas (Chile). Y, además, el provincialismo no debe identificarse con la voz o el giro de la «comarca de un país o nación», que serían más bien «comarcalismos».

Si seguimos la certera distinción de Gregorio Salvador expuesta más arriba, la macroestructura del diccionario debería contener solo provincialismos -que sean de una o varias provincias, extendidos y de uso frecuente con el reciente requisito académico de que «[el mantenimiento de estas entradas] pueda ser testimoniado por la documentación académica o a través de otras vías, especialmente la información proporcionada por los académicos españoles y de los países hispánicos» (2.2. xxxIV)-, y no localismos, aunque en tal requisito pueda objetarse también la imprecisión por «a través de otras vías» (la documentación académica es clara al buscarse la marca en el NTLLE) y por dejar la información dada a los académicos, ya que esta no es suficiente pero sí importante: la vigencia del término -la Academia habla, por el contrario, de «arcaísmos dialectales» que se excluyen en su repertorio (2.2. xxxIv)- la certifica el dialectólogo a partir de encuestas de campo.

2. A partir de las dos últimas ediciones electrónicas en CD-ROM (1992 y 2001) y del rastreo por el NTLLE, se han analizado cada uno de los provincialismos. Así el léxico marcado con la marca Córd. de la $22^{\mathrm{a}}$ edición (DRAE-2001) está formado por 17 lemas: 
1. agarbarse: prn. Córd. agacharse. 2. amolanchín: m. Alm., Córd., Gran., Jaén y Sev. amolador. 3. barril: 6. m. Alm., Córd. y Gran. Frasco de vidrio, botella. 4. descuidar: 5. intr. Cád., Córd. y Jaén. Dicho de una mujer: parir. 5. faisán ${ }^{1}$ : 3. m. Córd. y Sev. Hongo comestible de color pardo que se cría en los jarales. 6. gallinita: f. Ar., Burg., Córd. y Rioja. mariquita (insecto coleóptero). 7. ganga' ${ }^{2}$ 2. f. Alm., Córd., Gran. y Jaén. Arado tirado por una sola caballería. 8. Geranio [de sardina]: m. Ál. y Córd. geranio de hierro. 9. hormazo ${ }^{2}:$ 2. Córd. y Gran. carmen ${ }^{1}$ 10. lagareta: 3. f. Córd. Pocilga de cerdos. 11. peinilla: f. Córd. y Jaén. Lendrera o peine corto de dos hileras opuestas de dientes. 12. pintar: 16. intr. Córd., Gran., Jaén y Mál. Sembrar a golpe. 13. revezo: 4. m. Córd. Tercera parte de la obrada [Obrada: «Labor que en un día hace una persona cavando la tierra, o una yunta arándola» (acep. 1)]. 14. seda: 5. f. Córd. Enfermedad de algunos árboles frutales, especialmente del manzano, que consiste en una especie de tela de araña que sofoca la flor. 15. sufra: 2. f. Córd. y Pal. prestación personal. 16. trompillo: 2. m. Córd. y Jaén. Tocón de jara [Tocón ${ }^{1}$ : «m. Parte del tronco de un árbol que queda unida a la raíz cuando lo cortan por el pie»]. 17. verdear: 6. tr. Córd. y Sev. Coger la aceituna para consumirla como fruto.

Esta edición electrónica no incluye dos entradas con la marca de Córdoba añadida en definición, lo que sí ocurre en la de papel:

1. aranzada: $f$. Medida agraria de distinta equivalencia según las regiones. La de Castilla equivale a $4.472 \mathrm{~m}^{2}$; la de Córdoba a $3.672 \mathrm{~m}^{2} \cdot 2$. costumbre [holgazana]: f. Der. Práctica que duró en Córdoba hasta principios del siglo XIX, según la cual la mujer casada no participaba de los bienes gananciales, y que fue derogada por la Novísima Recopilación.

De otra parte, el léxico marcado en la $21^{\mathrm{a}}$ edición (DRAE-1992) está constituido por 15 lemas, de los cuales 13 llevan la marca Córd. (marca original en definición) y 2, Córdoba (marca añadida en definición) (Gómez 2003: 51-52): 
1. agraz: 8. Córd. agracejo, arbusto berberidáceo. 2. andrehuela: f. Córd. Especie de melón que se guarda para el invierno. 3. aranzada: f. Medida agraria de distinta equivalencia según las regiones. La de Castilla equivale a 4.472 metros cuadrados; la de Córdoba a 3.672. 4. barril: 3. Córd. y Gran. Frasco de vidrio, botella. 5. costumbre [holgazana]: Der. Práctica que duró en Córdoba hasta principios del siglo IX, según la cual la mujer casada no participaba de los bienes gananciales; costumbre derogada por la Novísima Recopilación. 6. gallinita: 2. Ar., Burg., Córd. y Rioja. mariqui$\mathrm{ta}^{1}$, insecto coleóptero. 7. geranio [de sardina]: Ál., Córd. y Nav. geranio de hierro. 8. hormazo2: 3. Córd. y Gran. carmen², quinta con jardín. 9. mamarón [ir a mamarones]: fr. Córd. Concurrir los trabajadores de una finca, sin previa invitación, a los bailes, juegos o reuniones que se celebran en las fincas próximas. 10. revezo: 4. Córd. Tercera parte de la obrada. 11. rezago: 2. Ar., Córd. y Chile. Reses débiles que se apartan del rebaño para procurar mejorarlas. 12. seda: 7. Córd. Enfermedad de algunos árboles frutales, especialmente del manzano, que consiste en una especie de tela de araña que sofoca la flor. 13. sufra: 2. Córd. y Pal. prestación personal. 14. temporera: f. Córd. Cante popular en las gañanías [Gañanía: «1. f. Conjunto de gañanes. 2. Casa en que se recogen»]. 15. trompillo: 2. Córd. Tocón de jara.

Nótese cómo la vigente edición ofrece importantes modificaciones en la macroestructura del diccionario que tienden a la reducción de los provincialismos (124 apariciones frente a las 151 anteriores) y de las voces generales andaluzas: 760 casos frente a las 995 precedentes. Por provincias, Jaén (de 6 a 15), Málaga (16 a 24) y Córdoba (19 a 15) suben, sobre todo las dos primeras; Almería (14 a 10), Cádiz (28 a 13), Granada (50 a 24) y Huelva (6 a 5) bajan; y Sevilla se mantiene: de 16 a 16.

Si se comparan ambas ediciones y se sigue el modelo de actualización de la Academia, se obtienen los siguientes cuadros:

\section{Cuadro 1}

\begin{tabular}{||l|l|l|}
\hline \multicolumn{1}{|c|}{ Provincialismo } & \multicolumn{1}{|c|}{ DRAE-1992 } & \multicolumn{1}{c|}{ DRAE-2001 } \\
\hline 1. Agarbarse & Presencia de acepción & $\begin{array}{l}\text { Adición de marca, enmienda de } \\
\text { acepción y enmienda de etimología }\end{array}$ \\
\hline 2. Agraz & $\begin{array}{l}\text { Presencia de marca Córd. } \\
\text { y acepción }\end{array}$ & $\begin{array}{l}\text { Enmienda de marca (And.) y mante- } \\
\text { nimiento de acepción }\end{array}$ \\
\hline 3. Amolanchín & Presencia de acepción & $\begin{array}{l}\text { Adición de marca y enmienda de } \\
\text { acepción }\end{array}$ \\
\hline
\end{tabular}




\begin{tabular}{|c|c|c|}
\hline Provincialismo & DRAE-1992 & DRAE-2001 \\
\hline 4. Andrehuela & Presencia de artículo & Supresión de artículo \\
\hline 5. Aranzada & $\begin{array}{l}\text { Presencia de marca en definición } \\
\text { y acepción }\end{array}$ & $\begin{array}{l}\text { Mantenimiento de marca en defini- } \\
\text { ción y enmienda de acepción }\end{array}$ \\
\hline 6. Barril & Presencia de marca y acepción & $\begin{array}{l}\text { Mantenimiento de marca y de acep- } \\
\text { ción y enmienda de etimología }\end{array}$ \\
\hline $\begin{array}{l}\text { 7. Costumbre } \\
\text { holgazana } \\
\text { (forma compleja) }\end{array}$ & $\begin{array}{l}\text { Presencia de marca en definición } \\
\text { y acepción }\end{array}$ & $\begin{array}{l}\text { Mantenimiento de marca en defini- } \\
\text { ción y enmienda de acepción y de eti- } \\
\text { mología }\end{array}$ \\
\hline 8. Descuidar & Presencia de acepción & $\begin{array}{l}\text { Adición de marca y enmienda de } \\
\text { acepción }\end{array}$ \\
\hline 9. Faisán ${ }^{1}$ & $\begin{array}{l}\text { Presencia de marca general anda- } \\
\text { luza (And.) y acepción }\end{array}$ & $\begin{array}{l}\text { Enmienda de marca (Córd. y Sev.), } \\
\text { enmienda de acepción y enmienda de } \\
\text { lema y de etimología }\end{array}$ \\
\hline 10. Gallinita & Presencia de marca y acepción & $\begin{array}{l}\text { Mantenimiento de marca y enmien- } \\
\text { da de acepción y de etimología }\end{array}$ \\
\hline 11. Ganga ${ }^{2}$ & $\begin{array}{l}\text { Presencia marca }(A l m .) \text { y de } \\
\text { acepción }\end{array}$ & $\begin{array}{l}\text { Enmienda de marca (Alm., Córd., } \\
\text { Gran. y Jaén) y mantenimiento de } \\
\text { acepción }\end{array}$ \\
\hline $\begin{array}{l}\text { 12. Geranio de } \\
\text { sardina } \\
\text { (forma compleja) }\end{array}$ & $\begin{array}{l}\text { Presencia de marca (Ál., Córd. y } \\
N a v .) \text { y acepción }\end{array}$ & $\begin{array}{l}\text { Enmienda de marca (Ál. y Córd), } \\
\text { mantenimiento de acepción y en- } \\
\text { mienda de etimología }\end{array}$ \\
\hline 13. Hormazo ${ }^{2}$ & Presencia de marca y acepción & $\begin{array}{l}\text { Mantenimiento de marca y enmien- } \\
\text { da de acepción }\end{array}$ \\
\hline 14. Lagareta & $\begin{array}{l}\text { Presencia de marca general anda- } \\
\text { luza (And.) y acepción }\end{array}$ & $\begin{array}{l}\text { Enmienda de marca (Córd.), mante- } \\
\text { nimiento de acepción y supresión de } \\
\text { etimología }\end{array}$ \\
\hline $\begin{array}{l}\text { 15. Mamarón } \\
\text { (ir a mamarones), } \\
\text { frase }\end{array}$ & $\begin{array}{l}\text { Presencia de forma compleja y } \\
\text { acepción }\end{array}$ & $\begin{array}{l}\text { Supresión de forma compleja y de } \\
\text { acepción }\end{array}$ \\
\hline 16. Peinilla & $\begin{array}{l}\text { Presencia de marca general anda- } \\
\text { luza (And.) y acepción }\end{array}$ & $\begin{array}{l}\text { Enmienda de marca (Córd. y Jaén) } \\
\text { y mantenimiento de acepción }\end{array}$ \\
\hline 17. Pintar & $\begin{array}{l}\text { Presencia de marca general anda- } \\
\text { luza (And.) y acepción }\end{array}$ & $\begin{array}{l}\text { Enmienda de marca (Cord., Gran., } \\
\text { Jaén y Mál.) y mantenimiento de } \\
\text { acepción }\end{array}$ \\
\hline 18. Revezo & Presencia de marca y acepción & Mantenimiento de marca y acepción \\
\hline 19. Rezago & $\begin{array}{l}\text { Presencia de marca (Ar., Córd. y } \\
\text { Chile) y acepción }\end{array}$ & $\begin{array}{l}\text { Enmienda de marca (supresión de } \\
\text { Córd.) y mantenimiento de acepción }\end{array}$ \\
\hline
\end{tabular}




\begin{tabular}{|c|c|c|}
\hline Provincialismo & $D R A E-1992$ & DRAE-2001 \\
\hline 20. Seda & Presencia de marca y acepción & Mantenimiento de marca y acepción \\
\hline 21. Sufra & Presencia de marca y acepción & $\begin{array}{l}\text { Mantenimiento de marca y acepción } \\
\text { y enmienda de etimología }\end{array}$ \\
\hline 22. Temporera & Presencia de artículo & Supresión de artículo \\
\hline 23. Trompillo & $\begin{array}{l}\text { Presencia de marca Córd. y acep- } \\
\text { ción }\end{array}$ & $\begin{array}{l}\text { Enmienda de marca (Córd. y Jaén) } \\
\text { y mantenimiento de acepción }\end{array}$ \\
\hline 24. Verdear & Presencia de acepción & $\begin{array}{l}\text { Adición de marca (Córd. y Sev.) y } \\
\text { enmienda de acepción }\end{array}$ \\
\hline
\end{tabular}

Cuadro 2

\begin{tabular}{|c|c|c|}
\hline Fenómeno & Lema o forma compleja & Número \\
\hline Mantenimiento de marca & $\begin{array}{l}\text { Aranzada, barril, costumbre [holgazana], gallinita, } \\
\text { hormazo }^{2}, \text { revezo, seda, sufra }\end{array}$ & 8 \\
\hline Adición de marca & Agarbarse, amolanchín, descuidar, verdear & 4 \\
\hline Adición de artículo & & 0 \\
\hline Adición de etimología & & 0 \\
\hline Adición de acepción & & 0 \\
\hline Adición de forma compleja & & 0 \\
\hline $\begin{array}{l}\text { Adición de acep. de forma } \\
\text { compleja }\end{array}$ & & 0 \\
\hline Supresión de artículo & Andrehuela, temporera & 2 \\
\hline Supresión de marca & Ver enmienda de marca & - \\
\hline Supresión de etimología & Lagareta & 1 \\
\hline Supresión de acepción & & 0 \\
\hline Supresión de forma compleja & Ir a mamarones & 1 \\
\hline $\begin{array}{l}\text { Supresión de acep. de forma } \\
\text { compleja }\end{array}$ & & 0 \\
\hline Enmienda de lema & Faisán $^{1}$ & 1 \\
\hline Enmienda de etimología & $\begin{array}{l}\text { Agarbarse, barril, costumbre [holgazana], faisán }{ }^{1} \text {, } \\
\text { gallinita, geranio [de sardina], sufra }\end{array}$ & 7 \\
\hline Mantenimiento de acepción & $\begin{array}{l}\text { Agraz, barril, ganga }{ }^{2} \text {, geranio [de sardina], horma- } \\
\text { zo }^{2} \text {, lagareta, peinilla, pintar, revezo, rezago, seda, } \\
\text { sufra, trompillo }\end{array}$ & 13 \\
\hline Enmienda de acepción & $\begin{array}{l}\text { Agarbarse, amolanchín, aranzada, costumbre [hol- } \\
\text { gazana], descuidar, faisán }{ }^{1} \text {, gallinita, hormazo }{ }^{2} \text {, } \\
\text { verdear }\end{array}$ & 9 \\
\hline Enmienda de marca & $\begin{array}{l}\text { Agraz, faisán }{ }^{1} \text {, ganga }{ }^{2} \text {, geranio [de sardina], laga- } \\
\text { reta, peinilla, pintar, rezago, trompillo }\end{array}$ & 9 \\
\hline
\end{tabular}


Cuadro 3

\begin{tabular}{||l|l|c||}
\hline \multicolumn{2}{|c|}{ Resumen } \\
\hline Total de mantenimiento & Marca y acepción & $21(=38.2 \%)$ \\
\hline Total de adiciones & Marca & $4(=7.3 \%)$ \\
\hline Total de supresiones & Artículo, etimología y forma compleja & $4(=7.3 \%)$ \\
\hline Total de enmiendas & Lema, etimología, acepción y marca & $26(=47.2 \%)$ \\
\hline TOTAL & & 55 \\
\hline $\begin{array}{l}\text { Total de mantenimiento, } \\
\text { adiciones y enmiendas }\end{array}$ & & $51(=92.7 \%)$ \\
\hline Total de supresiones & & $4(=7.3 \%)$ \\
\hline
\end{tabular}

Como se desprende, el laboreo académico entre las dos ediciones ha sido muy intenso -como dice Alonso Zamora Vicente (1988: 143)- no sólo por parte de las distintas comisiones, sino también por los académicos correspondientes. Son, pues, 24 artículos que contienen la marca cordobesa: 19 sustantivos y 5 verbos. Frente a la ausencia de nuevos artículos, etimología, acepción, forma compleja, se constata una preferencia por el mantenimiento, adiciones, enmiendas, frente a supresiones. Así, por ejemplo, tan solo se han suprimido dos artículos (andrehuela, temporera), una forma compleja (ir a mamarones) y una etimología (lagareta). Por el contrario, se han conservado ocho marcas dialectales (aranzada, barril, costumbre [holgazana], gallinita, hormazo ${ }^{2}$, revezo, seda, sufra) y trece acepciones: agraz, barril, ganga ${ }^{2}$, geranio (de sardina), hormazo ${ }^{2}$, lagareta, peinilla, pintar, revezo, rezago, seda, sufra, trompillo. Se han añadido cuatro marcas geográficas (agarbarse, amolanchín, descuidar, verdear) y se han enmendado en veintiséis casos como una enmienda de lema (faisán ${ }^{l}$ ), siete enmiendas de etimología (agarbarse, barril, costumbre [holgazana], faisán ${ }^{l}$, gallinita, geranio [de sardina], sufra), nueve enmiendas de acepción (agarbarse, amolanchín, aranzada, costumbre [holgazana], descuidar, faisán ${ }^{l}$, gallinita, hormazo ${ }^{2}$, verdear) y nueve enmiendas de marca: agraz, faisán ${ }^{l}$, ganga ${ }^{2}$, geranio [de sardina], lagareta, peinilla, pintar, rezago, trompillo.

Los artículos enmendados en cuanto a la marca unos son por la sustitución de la marca general andaluza (And.) por la cordobesa, como en agraz; o al revés, sustitución de la marca cordobesa y de otra provincia u otras provincias por la general andaluza -más frecuente-, como en faisán ${ }^{1}$, lagareta, peinilla, pintar; otros por la adición de la marca cordobesa y de otras provincias como en gang $a^{2}$; otros por la adición de la marca de otra provincia (trompillo); por la supresión de la marca cordobesa o de otra provincia: rezago o geranio (de sardina). 
3. Desde un punto de vista histórico, los provincialismos cordobeses empiezan a introducirse en los diccionarios académicos a principios del XIX. El primero de ellos es hormazo (Alvar Ezquerra 2000: 438), documentado en la cuarta edición de 1803. No será hasta final de la centuria cuando empiecen a tener continuidad en las dos últimas ediciones del siglo, 1884 y $1899\left(12^{\mathrm{a}}\right.$ y $\left.13^{\mathrm{a}}\right)$, en la que se constatan los términos andrehuela y aranzada respectivamente (Alvar Ezquerra 2000: 76). ${ }^{2}$ En la decimoquinta edición de 1925 los provincialismos serán cada vez más frecuentes (geranio [de sardina], rezago, seda, sufra, trompillo) (Alvar Ezquerra 2000: 404, 701, 726, 743 y 788 respectivamente) y de esta manera han ido incorporándose a la macroestructura del diccionario hasta hoy, especialmente en la última, como costumbre (holgazana), ir a mamarones, revezo, temporera (DRAE-1936; Alvar Ezquerra 2000: 282, 497, 699 y 760 respectivamente); barril (DRAE-1970S; Alvar Ezquerra 2000: 125); gallinita (DRAE-1984; Alvar Ezquerra 2000: 392) y agarbarse, amolanchín, descuidar, faisán ${ }^{1}$ (Alvar Ezquerra 2000: 371), ganga ${ }^{2}$, peinilla, pintar o verdear (DRAE-2001). Además, el diccionario manual también se ha hecho eco de ellos, como las primeras documentaciones del DMILE-1927: agraz ${ }^{3}$ y lagareta.

Por otra parte, algunos de estos provincialismos coinciden en el tiempo con el inicio del lema en la macroestructura del diccionario como en hormazo (DRAE-1803), andrehuela (DRAE-1884), ir a mamarones y temporera (DRAE-1936) o el reciente gallinita (DRAE-1984), o están muy próximos a la primera aparición de la entrada, como sufra (DRAE-1899, DRAE-1925), o más alejados: trompillo (DRAE-1822, DRAE1925), geranio [de sardina] (DRAE-1803, DRAE-1925).

4. Estos provincialismos se clasifican en varios tipos. En primer lugar, según tengan la marca exclusiva de Córdoba o sean compartidas también por otras provincias, como dijimos más arriba. Entre los primeros se encuentran agraz, andrehuela, costumbre [holgazana], ir a mamarones, revezo, seda, temporera, trompillo (DRAE1992) y agarbarse, costumbre [holgazana], lagareta, revezo, seda (DRAE-2001); entre los segundos, aranzada (Castilla, Córdoba), barril (Córdoba, Granada), gallinita (Aragón, Burgos, Córdoba, Rioja), geranio (de sardina) (Álava, Córdoba, Navarra), hormazo ${ }^{2}$ (Córdoba, Granada), rezago (Aragón, Córdoba, Chile), sufra (Córdoba, Palencia) (DRAE-1992) y amolanchín (Almería, Córdoba, Granada, Jaén, Sevilla), aranzada (Castilla, Córdoba), barril (Almería, Córdoba, Granada), descuidar (Cádiz, Córdoba, Jaén), faisán ${ }^{I}$ (Córdoba, Sevilla), gallinita (Aragón, Burgos, Córdoba, Rioja), ganga ${ }^{2}$ (Almería, Córdoba, Granada, Jaén), geranio (de sardina) (Álava, Córdoba),

2 Aranzada: Debería añadirse a Alvar Ezquerra (2000).

3 Agraz: Ibidem. 
hormazo² (Córdoba, Granada), peinilla (Córdoba, Jaén), pintar (Córdoba, Granada, Jaén, Málaga), sufra (Córdoba, Palencia), trompillo (Córdoba, Jaén) y verdear (Córdoba, Sevilla).

En segundo lugar, los provincialismos se clasifican según hayan tenido o no continuidad en los diccionarios. En tal sentido, son certeras las palabras de Salvador:

El método habitual de la lexicografía es el plagio, dicho sin ningún sentido peyorativo: es una realidad objetiva y fácilmente constatable. Lo que han hecho todos los diccionarios posteriores ha sido copiar la edición entonces vigente del Diccionario de la Academia, añadiendo algunas cosas aquí o allá, prescindiendo de otras y corrigiendo o actualizando definiciones (2003: 211-212).

De este modo hallamos, en primer lugar, marcas que, desde su incorporación al diccionario, han llegado hasta la vigente edición pasando por todos los tipos de diccionarios, usual, manual e histórico en su caso: aranzada (desde el DRAE-1899), barril (DRAE-1970S), ${ }^{4}$ hormazo ${ }^{2}$ (DRAE-1803), revezo (DRAE-1936), seda (DRAE1925), sufra (DRAE-1925), trompillo (DRAE-1925). ${ }^{6}$ En segundo lugar, marcas que han llegado hasta la edición de 1992 y que han sido suprimidas o enmendadas en 2001: agraz (desde DMILE-1927), andrehuela (DRAE-1884), ir a mamarones (DRAE1936), ${ }^{7}$ temporera $\left(D R A E\right.$-1936). ${ }^{8}$ En tercer lugar, marcas que han tenido alguna que otra interrupción como costumbre (holgazana) (desde 1936 a 2001), ${ }^{9}$ gallinita (desde el DRAE-1984 al DRAE-2001), ${ }^{10}$ geranio [de sardina] (desde el DRAE-1925 hasta el $D R A E$-2001), ${ }^{11}$ rezago (desde el DRAE-1925 al DRAE-1992). ${ }^{12}$

En tercer lugar, existen provincialismos que presentan marcas geográficas inestables como en lagareta cuya marca cordobesa (DMILE-1927) se ha recuperado en la última edición pasando por diferentes fases de vacilación con la marca andaluza general; ${ }^{13}$ faisán $^{l}$ (DRAE-2001) que desde DRAE-1936 a DRAE-1992 ha llevado la mar-

4 Se añade la marca Alm., junto a Córd. y Gran., en el DRAE-2001.

Pasa por todos los diccionarios, excepto el histórico.

6 Se añade la marca Jaén en el DRAE-2001.

7 No aparece en el DMILE-1950.

8 No aparece en el DMILE-1950, pero sí en el DMILE-1985 y el DMILE-1989 en donde se añade la marca Jaén. Se elimina el artículo en el DRAE-2001.

9 No aparece en el DMILE-1927 y el DMILE-1950.

10 Desaparece en DMILE-1984, pero reaparece en DMILE-1989.

11 Se quita en DMILE-1927, DRAE-1939, DRAE-1947.

12 Se quita en DMILE-1927, pero se mantiene la marca en el verbo rezagar.

13 En efecto, la marca Córd. -que se sustituye por And. en las ediciones usuales DRAE-1936, DRAE-1939, DRAE-1947, DRAE-1956, DRAE-1970, DRAE-1984, DRAE-1992 y manuales de DMILE1984 y DMILE-1989- reaparece tan solo en el DMILE-1950. 
ca And.; peinilla (DRAE-2001) que desde DRAE-1970S contiene también la marca general o el caso de pintar (DRAE-2001). Otra veces, hay provincialismos en donde se sustituye la expresión «En algunas regiones» o «En algunas partes» por la marca cordobesa como agarbarse (DRAE-2001) ${ }^{14}$ o verdear (DRAE-2001). ${ }^{15}$

5. Desde un punto de vista cognitivo, los provincialismos (19 nombres, 5 verbos y ningún adjetivo) se relacionan con el subdominio de actividades del campo con nombres, además, de plantas y animales o enfermedades, oficios: agraz, aranzada, gallinita, geranio [de sardina], hormazo ${ }^{2}$, revezo, rezago, seda, sufra, temporera, trompillo, amolanchín, faisán ${ }^{1}$, ganga ${ }^{2}$; de la casa: andrehuela, barril, lagareta, peinilla; o del derecho: costumbre (holgazana). Lo mismo le pasa a los verbos como ir a mamarones, pintar o verdear (campo), descuidar (familia) o el general agarbarse.

\section{REFERENCIAS BIBLIOGRÁFICAS}

Ahumada, Ignacio (1998): «Estudio preliminar» del Vocabulario andaluz de Antonio Alcalá Venceslada, ed. facsímil de la impresa por la Real Academia Española (1951), Jaén, Universidad de Jaén, pp. XI-XXXV.

Alvar, Manuel (1979): «Lengua, dialecto y otras cuestiones conexas», Lingüística española actual, I/1, pp. 5-29.

Alvar EzQuerra, Manuel (1984): «Los regionalismos en los diccionarios y vocabularios regionales», en Manuel Alvar, coord., Lenguas peninsulares y proyección hispánica, Madrid, Fundación Friedrich Ebert e Instituto de Cooperación Iberoamericana, pp. 175-197 [recogido en Lexicografia descriptiva, Barcelona, Biblograf, 1993, pp. 313-331].

- (2000): Tesoro léxico de las hablas andaluzas, Madrid, Arco/Libros.

CASARES, Julio (1944): El idioma como instrumento y el diccionario como símbolo, Madrid, Gráficas Barragán.

Fernández-Sevilla, Julio (1974): Problemas de lexicografía actual, Bogotá, Instituto Caro y Cuervo.

Gómez Solís, Felipe (2003): «Diccionario y comentario lexicográfico», en Manuel Galeote, ed., Córdoba lingüistica y literaria, Córdoba, Iznájar-Diputación Provincial de Córdoba, pp. 41-57.

14 La expresión «En algunas regiones» es del DRAE-1992.

15 La expresión «En algunas partes» es del DRAE-1970S. 
Lázaro Carreter, Fernando (1972): Crónica del Diccionario de Autoridades (1713-1740), Madrid, Real Academia Española.

Martínez Marín, Juan (1996): «Los vocabularios andaluces», en Ignacio Ahumada, ed., Vocabularios andaluces. Revisión crítica y perspectivas (II Seminario de Lexicografía Hispánica, Jaén, 28 y 29 de noviembre de 1995), Jaén, Universidad de Jaén, pp. 31-41.

DRAE-1992. Real Academia Española (1992): Diccionario de la lengua española (DRAE), Madrid [véase la ed. en CD-ROM, Madrid, 1995].

DRAE-2001. Real Academia Española (2001): Diccionario de la lengua española (DRAE), Madrid [véase la ed. en CD-ROM, Madrid, 2003].

NTLLE. Real Academia Española: Nuevo Tesoro Lexicográfico de la Lengua Española, buscón del portal www.rae.es.

Salvador, Gregorio (2003): «Los dialectalismos en los diccionarios», en María Antonia Martín Zorraquino y José Luis Aliaga Jiménez, eds., Lexicografía hispánica ante el siglo XXI. Balance y perspectivas (Actas del Encuentro de lexicógrafos celebrado en Zaragoza, en el marco del Centenario María Moliner, los días 4 y 5 de noviembre de 2002), Zaragoza, Institución Fernando el Católico, pp. 209-220.

Salvador Rosa, Aurora (1985): «Las localizaciones geográficas en el Diccionario de Autoridades», Lingüística española actual, VII/1, pp. 103-139.

Seco, Manuel (2003²): «Problemas formales de la definición lexicográfica», en Estudios de lexicografía española, Madrid, Gredos, pp. 25-46.

Zamora Vicente, Alonso (1988): «La Real Academia Española», en Al trasluz de la lengua actual, Madrid, Universidad Complutense, pp. 141-150. 